\title{
Keeping the engine primed: HIF factors as key regulators of cardiac metabolism and angiogenesis during ischemia
}

\author{
Ralph V. Shohet • Joseph A. Garcia
}

Received: 1 October 2007 /Revised: 22 October 2007 / Accepted: 23 October 2007 / Published online: 20 November 2007

(C) Springer-Verlag 2007

\begin{abstract}
Myocardial ischemia, the most common cause of cardiac hypoxia in clinical medicine, occurs when oxygen delivery cannot meet myocardial metabolic requirements in the heart. This deficiency can result from either a reduced supply of oxygen (decreased coronary bloodflow) or an increased myocardial demand for oxygen (increased wall stress or afterload). Patients with stable coronary artery disease as well as patients experiencing acute myocardial infarction can experience episodes of severe ischemia. Although hypoxia is an obligatory component, it is not the sole environmental stress experienced by the ischemic heart. Reperfusion after ischemia is associated with increased oxidative stress as the heart reverts to aerobic respiration and thereby generates toxic levels of reactive oxygen species (ROS). During mild ischemia, mitochondrial function is partially compromised and substrate preferences adapt to sustain adequate ATP generation. With severe ischemia, mitochondrial function is markedly compromised and anaerobic metabolism must provide energy no matter what the cost in generation of toxic ROS adducts. Ischemia produces a variety of environmental stresses that impair cardiovascular function. As a result, multiple signaling pathways are activated in mammalian cells during
\end{abstract}

\section{R. V. Shohet}

John A. Burns School of Medicine,

Center for Cardiovascular Research, University of Hawaii,

651 Ilalo St.,

Honolulu, HI 96813, USA

e-mail: shohet@hawaii.edu

\section{J. A. Garcia ( $\square)$}

Department of Internal Medicine, Molecular Cardiology Division, University of Texas Southwestern Medical Center at Dallas,

5323 Harry Hines Blvd.,

Dallas, TX 75390-8573, USA

e-mail: joseph.garcia@utsouthwestern.edu ischemia/reperfusion injury in an attempt to minimize cellular injury and maintain cardiac output. Amongst the transcriptional regulators activated are members of the hypoxia inducible factor (HIF) transcription factor family. HIF factors regulate a variety of genes that affect a myriad of cellular processes including metabolism, angiogenesis, cell survival, and oxygen delivery, all of which are important in the heart. In this review, we will focus on the metabolic and angiogenic aspects of HIF biology as they relate to the heart during ischemia. We will review the metabolic requirements of the heart under normal as well as hypoxic conditions, the effects of preconditioning and its regulation as it pertains to HIF biology, the apparent roles of HIF-1 and HIF-2 in intermediary metabolism, and translational applications of HIF-1 and HIF-2 biology to cardiac angiogenesis. Increased understanding of the role of HIFs in cardiac ischemia will ultimately influence clinical cardiovascular practice.

Keywords HIF · Hypoxia · Heart · Ischemia ·

Angiogenesis $\cdot$ Metabolism

\section{Myocardial fuel choice and oxygen supply}

A remarkable feature of the heart, one of the most metabolically active organs in the body, is its ability to use a wide variety of fuel substrates in aerobic respiration for energy production. Oxygen, delivered in blood through the coronary arteries, is efficiently extracted by the heart for generation of reducing equivalents by mitochondria, focal points for fatty acid or pyruvate oxidation, and for ketone body utilization [1]. Fuel choice in the adult heart is not homogenous under all conditions, but instead is highly dependent upon substrate availability as well as tissue oxygenation [2]. The adult heart preferentially uses fatty 
acids during times of adequate oxygen availability [2, 3]. This preference changes to glucose utilization via pyruvate oxidation in mild ischemia, if glucose is available, and to glycolysis during severe ischemia.

Aerobic respiration is an efficient means for generating energy, but it comes at a price. Reactive oxygen species (ROS) are generated under physiological conditions with the primary source being the mitochondrial electron transport chain. If left unchecked, elevated ROS lead to cumulative cellular damage induced by oxidative stress. ROS levels are markedly elevated during ischemia/reperfusion injury and perhaps during ischemia or hypoxia itself [4]. Following reperfusion, a naive heart experiences a profound increase in oxidative stress [5] and reduced aerobic energy production [6]. The mitochondria are both the major source [7] and the most affected subcellular component of ROS generated during ischemia/reperfusion [8, 9]. However, ROS also have a role in normal physiological processes, including cell growth and differentiation, vascular tone, and cardiac growth, due to signal transduction pathways activated by ROS [10, 11]. Hence, ROS homeostasis is essential for proper functioning of cardiac myocytes and other cells types in the basal as well as stressed state.

\section{Ischemia/reperfusion and preconditioning}

A protective response by the heart and other organs to sublethal levels of hypoxia or ischemia, known as preconditioning, results in the induction of adaptive physiological processes. This process is relevant not only to coronary artery patients experiencing repetitive ischemia due to coronary artery vasospasm or subocclusions, but also to diabetic patients with microvascular heart disease as well as to hypertensive and cardiomyopathic heart disease patients with increased myocardial wall stress and consequently greater oxygen demand. Ischemic preconditioning has an immediate as well as a delayed component $[12,13]$. The immediate preconditioning response occurs within minutes to hours [14] and is mediated by ion channels as well as by signaling molecules produced during ischemia [15]. The delayed preconditioning response, a transcriptional response lasting from hours to days, is conferred by de novo synthesized cellular factors [16].

The protective cellular processes induced by delayed preconditioning have been well studied and are aimed at optimizing oxygen delivery, intermediary metabolism, and preserving mitochondrial function. However, less is known about the regulatory network that confers delayed preconditioning [17]. With reperfusion or reoxygenation, as occurs during preconditioning, ROS levels increase and redoxsensitive transcription factors are activated. Being redox- sensitive transcription factors, HIF members are poised to exert significant control over the protective cellular response generated during delayed preconditioning. One protective response induced during the initial phase of delayed preconditioning is a shift from aerobic to glycolytic metabolism. For the severely ischemic heart, this is beneficial in the short-term, but is insufficient to meet its long-term needs.

To meet the long-term challenges during prolonged ischemia, the heart induces several protective effects aimed at restoring aerobic respiration. These effects include increased angiogenesis in an attempt to restore blood delivery to the ischemic heart as well as augmentation of mitochondrial respiration and mitochondrial biogenesis to maximize energy production from the available oxygen content [12]. Perhaps in anticipation of successfully restoring oxygen delivery to the hypoxic tissue, the ischemic heart also induces expression of endogenous cytoprotective cellular factors including antioxidant enzymes (AOE) that eliminate ROS in the mitochondria and other subcellular compartments [18]. Hence, a key target for preconditioning is the mitochondria [19], a central organelle with multiple biological roles in addition to energy generation [20]. Regulatory factors implicated in mitochondrial biogenesis have been identified [21]. As will be discussed, HIF members have been implicated in regulating the angiogenic and metabolic response to chronic ischemia. By contrast, the transcriptional regulation of the endogenous cytoprotective response remains poorly understood, although it is plausible that HIF members are likewise involved in regulation of this protective response.

\section{Preconditioning and transcriptional regulation of intermediary metabolism}

Changes in cardiac fuel substrate preference during ischemia have been delineated, but our knowledge of how substrate utilization is determined at the transcriptional level during chronic ischemia is sparse. The most wellstudied regulator of cardiac intermediary metabolism is $\operatorname{PPAR} \alpha$, the transcriptional factor controlling expression of proteins involved in fatty acid uptake, transport, derivation, and oxidation [22]. PPAR $\alpha$ signaling is impaired during hypoxia in neonatal cardiomyocytes as well as in hearts [23, 24], consistent with the observation that substrate preference shifts from fatty acid to glucose utilization during myocardial ischemia [25]. With respect to other mitochondrial substrates, our understanding of the regulation of factors involved in ketone body utilization is limited, despite its use during nutrient stress. Control of glucose use during oxygen availability is also not understood. By contrast, the transcriptional regulator of anaerobic 
glycolytic metabolism has been identified as HIF-1, a heterodimer comprised of HIF-1 alpha (HIF-1 $\alpha$ ) conferring biological specificity and HIF-1 beta (HIF-1 $\beta$ ) required for biological activity [26]. HIF members are transcriptional regulators of genes involved in hypoxic and other stress responses (Fig. 1) [27, 28]. With completion of the human genome project, a second HIF alpha member closely related to HIF- $1 \alpha$ in composition and regulation was identified, Endothelial PAS domain protein 1 (EPAS1), encoding HIF$2 \alpha$ [29]. Although a wealth of data has been generated about HIF-1 over the past decade, the founding member of the HIF family, less is known about HIF-2. Nevertheless, distinct and, in some cases, complementary roles are emerging with respect to HIF-1 and HIF-2.

\section{Biological roles for HIF-1 and HIF-2 in intermediary metabolism}

The role of HIF-1 appears to be the most important in the early phase after exposure to stress where a transition from aerobic to anaerobic metabolism is essential for cell survival. HIF-1 controls expression of cellular factors involved in glucose metabolism which allows cells to shift from aerobic metabolism to anaerobic glycolysis [30], a role analogous to PPAR $\alpha$ and its control of fatty acid metabolism. Elimination of HIF- $1 \alpha$ results in a muted glycolytic response to hypoxia [30], whereas the loss of HIF- $2 \alpha$ has no effect on glycolysis [31], consistent with a selective role for HIF- $1 \alpha$ in control of glycolytic enzyme gene expression. HIF-1 also affects mitochondrial-dependent metabolism by at least three mechanisms. First, HIF-1 induces

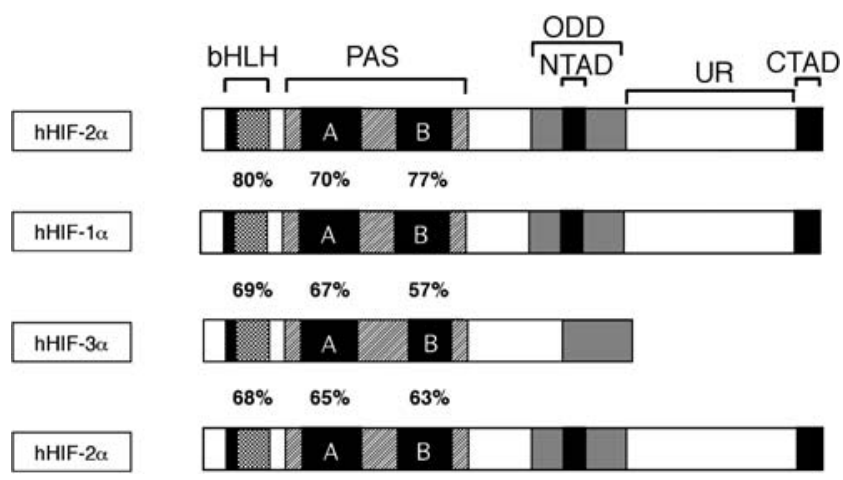

Fig. 1 Alignment of HIF- $1 \alpha$, HIF- $2 \alpha$, and HIF-3 $\alpha$. Homology (percent identity) comparisons of the conserved basic helix-loop-helix $(b H L H)$ and PAS-A,B repeats located within the PAS domain (PAS). Also indicated are the conserved amino-terminal activation domain $(N T A D)$ located within the oxygen-dependent degradation domain $(O D D)$ and the carboxy-terminal activation domain (CTAD) region. HIF- $1 \alpha$ and HIF- $2 \alpha$ have similar structural and regulatory features whereas spliced variants of HIF-3 $\alpha$ contain none or one (not shown) of the activation domains. The unique regions $(U R)$ may confer specific determinants of HIF- $1 \alpha$ and HIF- $2 \alpha$ activation
$P d k 1$ encoding pyruvate dehydrogenase kinase $1[32,33]$, a negative regulator of the pyruvate dehydrogenase complex $(\mathrm{PDH}) . \mathrm{PDH}$ is the nexus for pyruvate entry into the mitochondrial oxidation pathway. Thus, increases in Pdk1 levels results in inhibition of PDH activity, reduced entry of pyruvate into mitochondria, and a subsequent reduction of mitochondrial respiration. Second, HIF-1 inhibits mitochondrial respiration by altering composition of the cytochrome oxidase complex [34]. HIF-1 induces expression of COX4-2 and LON, with the net result being more efficient mitochondrial respiration during times of oxygen deficit. Third, HIF-1 acts in conjunction with c-myc to induce expression of HKII [35], a glycolytic enzyme that shifts glucose away from mitochondrial utilization and also has antioxidant effects [36].

HIF-2 appears to regulate processes that are important in more long-term adaptive or anticipatory responses. The latter include the desired, but potentially perilous, transition back to an oxygenated state. HIF-2 functions to maintain mitochondrial homeostasis by regulating production of cellular factors that alleviate oxidative stress [37, 38]. HIF- $2 \alpha$ null mice exhibit multiple organ pathology resembling a mitochondrial disease state as well as abnormal liver mitochondrial function $[37,38]$. The biochemical basis for the HIF- $2 \alpha$ null phenotype in liver involves increased oxidative stress due to reduced expression of antioxidant enzyme (AOE) genes including Sod2 [38], encoding an essential modulator of mitochondrial oxidative stress [39, 40], and Frataxin [37], encoding the oxidative stressregulated chaperone protein for mitochondrial aconitase. Thus, whereas HIF-1 is a pathway regulator of genes encoding glycolytic enzymes, HIF-2 regulates production of factors important for maintaining mitochondrial homeostasis. Whether these findings for HIF- $2 \alpha$ in the liver hold true for the heart is unknown.

\section{Biological roles for HIF-1 and HIF-2 in cardiac angiogenesis}

Hypoxia and HIF factors have been implicated as master regulators of cardiovascular development [41, 42]. Although HIF-1 and HIF-2 may have overlapping transcriptional regulation of proangiogenic genes, transgenic mouse studies support specific activities for HIF-1 and HIF-2 in vascular development that includes stage-, cell-, and tissuespecific roles. Global HIF-1 $\alpha$ knockout mice have abnormal vascular as well as cardiac development $[43,44]$. In comparison, global HIF- $2 \alpha$ knockout embryos have more subtle vascular defects [45]. A dominant negative form of HIF- $1 \alpha$ that interferes with both HIF-1 and HIF-2 signaling impairs vascular development in the embryo when expressed in vascular endothelial cells [46]. Cardiomyocyte- 
specific HIF-1 $\alpha$ knockout mice have lower capillary densities and reduced expression of proangiogenic factors [47]; it has not been reported whether endothelial cellspecific HIF-1 $\alpha$ knockout mice have any cardiac vascular phenotype [48]. Restoration of HIF- $2 \alpha$ expression in endothelial cells of global HIF- $2 \alpha$ knockout mice does not fully rescue the HIF- $2 \alpha$ null vascular phenotype [49], suggesting that HIF- $2 \alpha$ expression in other cell types may be required for normal vascular development.

Translational experiments support potential therapeutic roles for HIF-1 and HIF-2 in cardiac angiogenesis. In cell culture models, HIF- $1 \alpha$ or HIF- $2 \alpha$ over-expression results in increased gene expression of a variety of proangiogenic factors in macrophages [50], cardiomyocytes [51], and vascular endothelial cells [52-55], cell types relevant to the ischemic and infarcted myocardium. Transgenic mice overexpressing HIF- $1 \alpha$ in the heart and subjected to myocardial infarction have increased capillary density in the infarct and peri-infarct zones [56]. Gene delivery of constitutively active HIF- $1 \alpha$ in a rat myocardial infarct model reduces infarct size and increases neoangiogenesis in the peri-infarct zone [57]. Knockout mice lacking the gene encoding the HIF prolyl hydroxylase PHD2, the enzyme targeting HIF alpha proteins for degradation during normoxia, have elevated levels of HIF-1 $\alpha$, increased number of mature medium-sized vessels, and enlarged capillaries in the subendocardial region [58]. A potential role for HIF-1 in cardiac vessel formation in human hearts is supported by the finding that a HIF- $1 \alpha$ polymorphism is associated with reduced coronary artery collateral formation, although the mechanism behind this observation remains to be determined [59].

\section{Relevance of HIF factors to cardiac ischemia/ reperfusion injury}

Environmental conditions present in ischemia/reperfusion are of direct relevance to HIF biology. HIF proteins are activated by oxidative stress [60-63]. HIF proteins are increased in the peri-infarct area after myocardial infarction in rats [64] and humans [65-67] with HIF-2 $\alpha$ expression occurring in remote areas from the infarct [64] suggesting a broader role for HIF-2 in ischemia/reperfusion biology. HIF- $2 \alpha$ has several unique aspects pertinent to oxidative stress and ischemia/reperfusion biology. DNA binding activity of HIF- $2 \alpha$, but not HIF- $1 \alpha$, may be differentially regulated by redox conditions [68]. As mentioned previously, HIF- $2 \alpha$ in vivo regulates major AOE and Frataxin gene expression in the liver [37, 38], cellular factors intimately involved in ROS and mitochondrial homeostasis in the heart [69]. More recently, studies with a HIF-2 $\alpha$ knockdown model identified a role for HIF-2 in protection against ischemia/reperfusion injury in the kidney ascribed to HIF-2 regulation of major AOE gene expression [70], confirming the earlier findings of HIF-2 regulation of AOE gene expression.

Although it has been recognized for a decade that HIF transcription factors are activated by environmental stress, the role of HIF members in cardiac ischemic injury remains unknown. Stabilization of HIF members by proteins that modulate HIF stability [71] or by siRNA directed against PHD2 [72] provides protection against ischemia-induced damage. Over-expression of constitutively active HIF-1 in rat cardiomyocytes confers resistance against ischemia/ reperfusion injury in a cell culture model [73]. HIF-1 over-expression in mice reduces infarct size and results in improved cardiac function after myocardial infarction [56]. Yet whether endogenous HIF member(s) confer this protective response during preconditioning is unknown. Mice partially deficient in HIF-1 have increased susceptibility to cardiac ischemia/reperfusion injury after whole animal hypoxia exposure [74], but this has been attributed to impaired induction of renal erythropoietin. Additional research will be needed to identify which HIF member(s) are important in the cardiac preconditioning response and whether HIF factors play an active role locally in the heart.

\section{Conclusion and future perspectives}

Cardiovascular diseases are leading causes of morbidity and mortality in the USA and western world. In the USA, acute and chronic treatments of cardiovascular disease states accounts for a substantial portion of USA healthcare expenditures. While conditions leading to myocardial injury have been well studied, endogenous protective responses that preserve cellular and organelle function, particularly mitochondria, during ischemia are poorly understood and thus are not targeted in current therapeutic strategies. The roles for HIF-1 and HIF-2 in myocardial ischemia are currently a largely undefined area of HIF biology. HIF-1 likely regulates glucose utilization in the heart during oxygen deprivation and may play a critical role in regulation of the angiogenic response after myocardial injury. HIF-2 has a complementary role to HIF-1 in regulation of intermediary metabolism in the liver, although its role in the heart remains to be defined, and may also be important in the angiogenic response of the heart. A clearer picture of the roles of HIF-1 and HIF-2 in cardiac biology will emerge with active investigation. If HIF factors prove to be essential factors that orchestrate protective cellular responses to cardiac ischemia, then studies of HIF signaling in the heart may lead to improved prevention or treatment of cardiovascular diseases using focused drug discovery approaches. 
Acknowledgement We gratefully acknowledge funding support from Amgen, United Mitochondrial Disease Foundation, March of Dimes (6-FY06-319), American Heart Association/Texas Affiliate (0465047Y), and National Institutes of Health (HL080532, HL073449, RR16453, AR050597-01A1, 1P50MH66172).

\section{References}

1. Taegtmeyer H (2000) Metabolism-the lost child of cardiology. J Am Coll Cardiol 36:1386-1388

2. Neely JR, Rovetto MJ, Oram JF (1972) Myocardial utilization of carbohydrate and lipids. Prog Cardiovasc Dis 15:289-329

3. Nieth H, Schollmeyer P (1966) Substrate-utilization of the human kidney. Nature 209:1244-1245

4. Goswami SK, Maulik N, Das DK (2007) Ischemia-reperfusion and cardioprotection: a delicate balance between reactive oxygen species generation and redox homeostasis. Ann Med 39:275-289

5. Ferrari R, Alfieri O, Curello S, Ceconi C, Cargnoni A, Marzollo P, Pardini A, Caradonna E, Visioli O (1990) Occurrence of oxidative stress during reperfusion of the human heart. Circulation 81:201-211

6. Ferreira R, Llesuy S, Milei J, Scordo D, Hourquebie H, Molteni L, de Palma C, Boveris A (1988) Assessment of myocardial oxidative stress in patients after myocardial revascularization. Am Heart J 115:307-312

7. Das DK, George A, Liu XK, Rao PS (1989) Detection of hydroxyl radical in the mitochondria of ischemic-reperfused myocardium by trapping with salicylate. Biochem Biophys Res Commun 165:1004-1009

8. Sadek HA, Nulton-Persson AC, Szweda PA, Szweda LI (2003) Cardiac ischemia/reperfusion, aging, and redox-dependent alterations in mitochondrial function. Arch Biochem Biophys 420:201-208

9. Ambrosio G, Zweier JL, Flaherty JT (1991) The relationship between oxygen radical generation and impairment of myocardial energy metabolism following post-ischemic reperfusion. J Mol Cell Cardiol 23:1359-1374

10. Soberman RJ (2003) The expanding network of redox signaling: new observations, complexities, and perspectives. J Clin Invest 111:571-574

11. Sen CK, Packer L (1996) Antioxidant and redox regulation of gene transcription. Faseb J 10:709-720

12. McLeod CJ, Pagel I, Sack MN (2005) The mitochondrial biogenesis regulatory program in cardiac adaptation to ischemia-a putative target for therapeutic intervention. Trends Cardiovasc Med $15: 118-123$

13. Arstall MA, Zhao YZ, Hornberger L, Kennedy SP, Buchholz RA, Osathanondh R, Kelly RA (1998) Human ventricular myocytes in vitro exhibit both early and delayed preconditioning responses to simulated ischemia. J Mol Cell Cardiol 30:1019-1025

14. Yellon DM, Baxter GF (1995) A "second window of protection" or delayed preconditioning phenomenon: future horizons for myocardial protection? J Mol Cell Cardiol 27:1023-1034

15. Murry CE, Jennings RB, Reimer KA (1986) Preconditioning with ischemia: a delay of lethal cell injury in ischemic myocardium. Circulation 74:1124-1136

16. Das DK, Moraru II, Maulik N, Engelman RM (1994) Gene expression during myocardial adaptation to ischemia and reperfusion. Ann N Y Acad Sci 723:292-307

17. Kodde IF, van der Stok J, Smolenski RT, de Jong JW (2007) Metabolic and genetic regulation of cardiac energy substrate preference. Comp Biochem Physiol A Mol Integr Physiol 146:26-39

18. Marczin N, El-Habashi N, Hoare GS, Bundy RE, Yacoub M (2003) Antioxidants in myocardial ischemia-reperfusion injury: therapeutic potential and basic mechanisms. Arch Biochem Biophys 420:222-236

19. Halestrap AP, Clarke SJ, Khaliulin I (2007) The role of mitochondria in protection of the heart by preconditioning. Biochim Biophys Acta 1767:1007-1031

20. Marin-Garcia J, Goldenthal MJ (2004) Heart mitochondria signaling pathways: appraisal of an emerging field. J Mol Med 82:565-578

21. Das DK, Maulik N, Sato M, Ray PS (1999) Reactive oxygen species function as second messenger during ischemic preconditioning of heart. Mol Cell Biochem 196:59-67

22. Watanabe K, Fujii H, Takahashi T, Kodama M, Aizawa Y, Ohta Y, Ono T, Hasegawa G, Naito M, Nakajima T, Kamijo Y, Gonzalez FJ, Aoyama T (2000) Constitutive regulation of cardiac fatty acid metabolism through peroxisome proliferator-activated receptor alpha associated with age-dependent cardiac toxicity. J Biol Chem 275:22293-22299

23. Huss JM, Levy FH, Kelly DP (2001) Hypoxia inhibits the peroxisome proliferator-activated receptor alpha/retinoid X receptor gene regulatory pathway in cardiac myocytes: a mechanism for O2-dependent modulation of mitochondrial fatty acid oxidation. $\mathrm{J}$ Biol Chem 276:27605-27612

24. Razeghi P, Young ME, Abbasi S, Taegtmeyer H (2001) Hypoxia in vivo decreases peroxisome proliferator-activated receptor alpha-regulated gene expression in rat heart. Biochem Biophys Res Commun 287:5-10

25. Bolukoglu H, Goodwin GW, Guthrie PH, Carmical SG, Chen TM, Taegtmeyer H (1996) Metabolic fate of glucose in reversible low-flow ischemia of the isolated working rat heart. Am J Physiol 270:H817-H826

26. Wang GL, Jiang BH, Rue EA, Semenza GL (1995) Hypoxiainducible factor 1 is a basic-helix-loop-helix-PAS heterodimer regulated by cellular $\mathrm{O} 2$ tension. Proc Natl Acad Sci USA 92:5510-5514

27. Semenza GL (2001) Hypoxia-inducible factor 1: oxygen homeostasis and disease pathophysiology. Trends in Molecular Medicine $7: 345-350$

28. Semenza GL (2000) HIF-1 and human disease: one highly involved factor. Genes \& Development 14:1983-1991

29. Tian SL, McKnight SL, Russell DW (1997) Endothelial PAS domain protein 1 (EPAS1), a transcription factor selectively expressed in endothelial cells. Genes Dev 11:72-82

30. Seagroves TN, Ryan HE, Lu H, Wouters BG, Knapp M, Thibault P, Laderoute K, Johnson RS (2001) Transcription factor HIF-1 is a necessary mediator of the pasteur effect in mammalian cells. Mol Cell Biol 21:3436-3444

31. Hu CJ, Wang LY, Chodosh LA, Keith B, Simon MC (2003) Differential roles of hypoxia-inducible factor 1alpha (HIF-1alpha) and HIF-2alpha in hypoxic gene regulation. Mol Cell Biol 23:9361-9374

32. Kim JW, Tchernyshyov I, Semenza GL, Dang CV (2006) HIF-1mediated expression of pyruvate dehydrogenase kinase: a metabolic switch required for cellular adaptation to hypoxia. Cell Metab 3:177-185

33. Papandreou I, Cairns RA, Fontana L, Lim AL, Denko NC (2006) HIF-1 mediates adaptation to hypoxia by actively downregulating mitochondrial oxygen consumption. Cell Metab 3:187-197

34. Fukuda R, Zhang H, Kim JW, Shimoda L, Dang CV, Semenza GL (2007) HIF-1 regulates cytochrome oxidase subunits to optimize efficiency of respiration in hypoxic cells. Cell 129:111-122

35. Kim JW, Gao P, Liu YC, Semenza GL, Dang CV (2007) HIF-1 and dysregulated c-Myc cooperatively induces VEGF and metabolic switches, HK2 and PDK1. Mol Cell Biol 27:7381-7393

36. Ahmad A, Ahmad S, Schneider BK, Allen CB, Chang LY, White CW (2002) Elevated expression of hexokinase II protects human lung epithelial-like A549 cells against oxidative injury. Am J Physiol Lung Cell Mol Physiol 283:L573-L584 
37. Oktay Y, Dioum E, Matsuzaki S, Ding K, Yan LJ, Haller RG, Szweda LI, Garcia JA (2007) Hypoxia-inducible factor 2alpha regulates expression of the mitochondrial aconitase chaperone protein frataxin. J Biol Chem 282:11750-11756

38. Scortegagna M, Ding K, Oktay Y, Gaur A, Thurmond F, Yan LJ, Marck BT, Matsumoto AM, Shelton JM, Richardson RA, Bennett MJ, Garcia JA (2003) Multiple organ pathology, metabolic abnormalities and impaired homeostasis of reactive oxygen species in Epas1-/- mice. Nat Genet 35:331-340

39. Harris ED (1992) Regulation of antioxidant enzymes. Faseb J 6:2675-2683

40. Rabilloud T, Heller M, Rigobello MP, Bindoli A, Aebersold CW, Lunardi J (2001) The mitochondrial antioxidant defence system and its response to oxidative stress. Proteomics 1:1105-1110

41. Lee YM, Jeong CH, Koo SY, Son MJ, Song HS, Bae SK, Raleigh JA, Chung HY, Yoo MA, Kim KW (2001) Determination of hypoxic region by hypoxia marker in developing mouse embryos in vivo: a possible signal for vessel development. Dev Dyn 220:175-186

42. Wikenheiser J, Doughman YQ, Fisher SA, Watanabe M (2006) Differential levels of tissue hypoxia in the developing chicken heart. Dev Dyn 235:115-123

43. Iyer NV, Kotch LE, Agani F, Leung SW, Laughner E, Wenger RH, Gassmann M, Gearhart JD, Lawler AM, Yu AY, Semenza GL (1998) Cellular and developmental control of O2 homeostasis by hypoxia-inducible factor 1 alpha. Genes Dev 12:149-162

44. Compernolle V, Brusselmans K, Franco D, Moorman A, Dewerchin M, Collen D, Carmeliet P (2003) Cardia bifida, defective heart development and abnormal neural crest migration in embryos lacking hypoxia-inducible factor-1alpha. Cardiovasc Res 60:569-579

45. Peng J, Zhang L, Drysdale L, Fong GH (2000) The transcription factor EPAS-1/hypoxia-inducible factor 2alpha plays an important role in vascular remodeling. Proc Natl Acad Sci USA 97:83868391

46. Licht AH, Muller-Holtkamp F, Flamme I, Breier G (2006) Inhibition of hypoxia-inducible factor activity in endothelial cells disrupts embryonic cardiovascular development. Blood 107:584-590

47. Huang Y, Hickey RP, Yeh JL, Liu D, Dadak A, Young LH, Johnson RS, Giordano FJ (2004) Cardiac myocyte-specific HIF-1alpha deletion alters vascularization, energy availability, calcium flux, and contractility in the normoxic heart. Faseb J 18:1138-1140

48. Tang N, Wang L, Esko J, Giordano FJ, Huang Y, Gerber HP, Ferrara N, Johnson RS (2004) Loss of HIF-1alpha in endothelial cells disrupts a hypoxia-driven VEGF autocrine loop necessary for tumorigenesis. Cancer Cell 6:485-495

49. Duan LJ, Zhang-Benoit Y, Fong GH (2005) Endothelium-intrinsic requirement for Hif-2alpha during vascular development. Circulation 111:2227-2232

50. White JR, Harris RA, Lee SR, Craigon MH, Binley K, Price T, Beard JL, Mundy CR, Naylor S (2004) Genetic amplification of the transcriptional response to hypoxia as a novel means of identifying regulators of angiogenesis. Genomics 83:1-8

51. Jiang C, Lu H, Vincent KA, Shankara S, Belanger AJ, Cheng SH, Akita GY, Kelly RA, Goldberg AM, Gregory RJ (2002) Gene expression profiles in human cardiac cells subjected to hypoxia or expressing a hybrid form of HIF-1 alpha. Physiol Genomics 8:23-32

52. Takeda N, Maemura K, Imai Y, Harada T, Kawanami D, Nojiri T, Manabe I, Nagai R (2004) Endothelial PAS domain protein 1 gene promotes angiogenesis through the transactivation of both vascular endothelial growth factor and its receptor, Flt-1. Circ Res 95:146-153

53. Kelly BD, Hackett SF, Hirota K, Oshima Y, Cai Z, Berg-Dixon S, Rowan A, Yan Z, Campochiaro ZA, Semenza GL (2003) Cell type-specific regulation of angiogenic growth factor gene expression and induction of angiogenesis in nonischemic tissue by a constitutively active form of hypoxia-inducible factor 1 . Circ Res 93:1074-1081

54. Manalo DJ, Rowan A, Lavoie T, Natarajan L, Kelly BD, Ye SQ, Garcia JG, Semenza GL (2005) Transcriptional regulation of vascular endothelial cell responses to hypoxia by HIF-1. Blood 105:659-669

55. Yamakawa M, Liu LX, Date T, Belanger AJ, Vincent KA, Akita GY, Kuriyama T, Cheng SH, Gregory RJ, Jiang C (2003) Hypoxia-inducible factor-1 mediates activation of cultured vascular endothelial cells by inducing multiple angiogenic factors. Circ Res 93:664-673

56. Kido M, Du L, Sullivan CC, Li X, Deutsch R, Jamieson SW, Thistlethwaite PA (2005) Hypoxia-inducible factor 1-alpha reduces infarction and attenuates progression of cardiac dysfunction after myocardial infarction in the mouse. J Am Coll Cardiol 46:2116-2124

57. Shyu KG, Wang MT, Wang BW, Chang CC, Leu JG, Kuan P, Chang $H$ (2002) Intramyocardial injection of naked DNA encoding HIF-1alpha/VP16 hybrid to enhance angiogenesis in an acute myocardial infarction model in the rat. Cardiovasc Res $54: 576-583$

58. Takeda K, Cowan A, Fong GH (2007) Essential role for prolyl hydroxylase domain protein 2 in oxygen homeostasis of the adult vascular system. Circulation 116:774-781

59. Resar JR, Roguin A, Voner J, Nasir K, Hennebry TA, Miller JM, Ingersoll R, Kasch LM, Semenza GL (2005) Hypoxia-inducible factor 1alpha polymorphism and coronary collaterals in patients with ischemic heart disease. Chest 128:787-791

60. Chandel NS, McClintock DS, Feliciano CE, Wood TM, Melendez JA, Rodriguez AM, Schumacker PT (2000) Reactive oxygen species generated at mitochondrial complex III stabilize hypoxiainducible factor-1alpha during hypoxia: a mechanism of $\mathrm{O} 2$ sensing. J Biol Chem 275:25130-25138

61. Haddad JJ, Land SC (2001) A non-hypoxic, ROS-sensitive pathway mediates TNF-alpha-dependent regulation of HIF-1alpha. FEBS Lett 505:269-274

62. Huang LE, Arany Z, Livingston DM, Bunn HF (1996) Activation of hypoxia-inducible transcription factor depends primarily upon redox-sensitive stabilization of its alpha subunit. J Biol Chem 271:32253-32259

63. Wang GL, Jiang BH, Semenza GL (1995) Effect of altered redox states on expression and DNA-binding activity of hypoxiainducible factor 1. Biochem Biophys Res Commun 212:550-556

64. Jurgensen JS, Rosenberger S, Wiesener MS, Warnecke C, Horstrup JH, Grafe M, Philipp S, Griethe W, Maxwell PH, Frei U, Bachmann S, Willenbrock R, Eckardt KU (2004) Persistent induction of HIF-1alpha and -2alpha in cardiomyocytes and stromal cells of ischemic myocardium. Faseb J 18:1415-1417

65. Blanco Pampin J, Garcia Rivero SA, Otero Cepeda XL, Vazquez Boquete A, Forteza Vila J, Hinojal Fonseca R (2006) Immunohistochemical expression of HIF-1alpha in response to early myocardial ischemia. J Forensic Sci 51:120-124

66. Lee SH, Wolf PL, Escudero R, Deutsch R, Jamieson SW, Thistlethwaite PA (2000) Early expression of angiogenesis factors in acute myocardial ischemia and infarction. $\mathrm{N}$ Engl $\mathrm{J}$ Med 342:626-633

67. Parisi Q, Biondi-Zoccai GG, Abbate A, Santini D, Vasaturo F, Scarpa S, Bussani R, Leone AM, Petrolini A, Silvestri F, Biasucci LM, Baldi A (2005) Hypoxia inducible factor-1 expression mediates myocardial response to ischemia late after acute myocardial infarction. Int J Cardiol 99:337-339

68. Lando D, Pongratz I, Poellinger L, Whitelaw ML (2000) A redox mechanism controls differential DNA binding activities of hypoxia-inducible factor (HIF) 1alpha and the HIF-like factor. J Biol Chem 275:4618-4627 
69. Venardos KM, Kaye DM (2007) Myocardial ischemia-reperfusion injury, antioxidant enzyme systems, and selenium: a review. Curr Med Chem 14:1539-1549

70. Kojima I, Tanaka T, Inagi R, Kato H, Yamashita T, Sakiyama A, Ohneda O, Takeda N, Sata M, Miyata T, Fujita T, Nangaku M (2007) Protective role of hypoxia-inducible factor-2alpha against ischemic damage and oxidative stress in the kidney. J Am Soc Nephrol 18:1218-1226

71. Muinck ED, Nagy N, Tirziu D, Murakami M, Gurusamy N, Goswami SK, Ghatpande S, Engelman RM, Simons M, Das DK (2007) Protection against myocardial ischemia-reperfusion injury by the angiogenic Masterswitch protein PR 39 gene therapy: the roles of HIF1alpha stabilization and FGFR1 signaling. Antioxid Redox Signal 9:437-445
72. Natarajan R, Salloum FN, Fisher BJ, Kukreja RC, Fowler AA 3rd (2006) Hypoxia inducible factor-1 activation by prolyl 4hydroxylase-2 gene silencing attenuates myocardial ischemia reperfusion injury. Circ Res 98:133-140

73. Date T, Mochizuki S, Belanger AJ, Yamakawa M, Luo Z, Vincent KA, Cheng SH, Gregory RJ, Jiang C (2005) Expression of constitutively stable hybrid hypoxia-inducible factor1alpha protects cultured rat cardiomyocytes against simulated ischemia-reperfusion injury. Am J Physiol Cell Physiol 288: C314-C320

74. Cai Z, Manalo DJ, Wei G, Rodriguez ER, Fox-Talbot K, Lu H, Zweier JL, Semenza GL (2003) Hearts from rodents exposed to intermittent hypoxia or erythropoietin are protected against ischemia-reperfusion injury. Circulation 108:79-85 